Expl Agric. (1992), volume 28, pp. 351-367

Printed in Great Britain

\title{
PRODUCTION POSSIBILITY FRONTIERS AND ESTIMATION OF COMPETITION EFFECTS: THE USE OF A PRIORI INFORMATION ON BIOLOGICAL PROCESSES IN INTERCROPPING
}

\author{
By RADHA RANGANATHAN $\dagger$ \\ Department of Theoretical Production Ecology, Wageningen Agricultural \\ University, Wageningen, The Netherlands
}

(Accepted 2 Dece,ber 1991)

\begin{abstract}
SUMMARY
Production possibility frontiers contribute much to an economic evaluation of yield advantages from intercropping. The difficulty with estimating a production frontier empirically from experimental data is one of ascertaining that the fitted curve corresponds with the frontier. This problem has been overcome by deriving the frontier from a priori knowledge of the biological processes that determine the outcome in intercropping. The hyperbolic relationship between biomass yield and plant density, and the parameters that characterize the degree of intra- and inter-specific competition in intercropping are used in this paper to derive production possibility frontiers. The method is illustrated with data from three intercropping studies. A brief review of the two main methods used by researchers to evaluate the results of intercropping, and their limitations, is also presented.
\end{abstract}

Fronteras de posibilidad de producción

\section{RESUMEN}

Las fronteras de posibilidad de producción contribuyen extensamente a la evaluación de las ventajas de rendimiento de la siembra simultánea. La dificultad de estimar una frontera de producción en forma empírica a partir de datos experimentales reside en verificar que la curva fijada se corresponde con la frontera. Este problema se ha podido solucionar mediante la derivación de la frontera a partir de conocimientos a priori acerca de los procesos biológicos que determinan el resultado de una siembra simultánea. En este artículo se utiliza la relación hiperbólica entre el rendimiento de biomasa y la densidad de la planta, y los parámetros que caracterizan el grado de competición intra e interespecífica dentro de la siembra simultánea para derivar fronteras de posibilidad de producción. El método está ilustrado mediante datos provenientes de tres estudios de siembra simultánea. También se presenta una breve reseña de los dos métodos principales utilizados por los investigadores para evaluar los resultados de la siembra simultánea.

\section{INTRODUCTION}

Natural plant populations are usually mixtures of species, within which individuals and species are interacting with each other. The description and quantification of these interactions form the subject of a specialized area of study called population ecology (Hart, 1986). Plants growing together influence each other by changing their environment, that is, by affecting conditions such as temperature,

$\nmid$ Present address: ICRISAT, Patancheru 502 324, AP, India. 
availability of sunlight or wind movement. They may also compete for soil nutrients and water.

Plant population dynamics take into account such interactions within the mixture by answering questions such as: how does the presence of species $A$ affect the growth and yield of species $B$, how does $B$ affect $A$, and does the effect of $B$ on $A$ and $A$ on $B$ change with changes in proportions and densities of the species?

Mixed cropping, a centuries-old technique of farming, has parallels with basic ecological principles relating to plant interactions. Farmers in the developing world have been growing two or more crops together on the same piece of land for reasons such as better exploitation of the environment, reducing risk, controlling weeds, spreading labour demand and satisfying dietary requirements. Research in mixed cropping has tried to provide an understanding of how to improve the productivity of these systems. The question asked is similar to those in the study of population dynamics in ecology: what is the nature of the interaction between species in a mixed crop?

The outcome of mutual interaction within a mixture is, in general, a reduction in plant growth and performance of both species. Yet, in a number of instances, mixed cropping has been seen to have advantages over sole cropping because total production is greater than either crop grown alone (Willey, 1979a, b; ICRISAT, 1981a). Various methods or indices for quantifying such yield benefits have been described and used extensively, but all have their particular advantages and disadvantages. In this paper, the main methods are reviewed and an alternative method, which overcomes some of the weaknesses of the existing ones, is proposed. This combines a physiological model, which expresses the yield of the crops in an intercrop as a function of their population densities, with the concept of production possibility frontiers from economics. The method is illustrated with the help of data from intercropping experiments and some of the economic interpretations that can be made using the method are briefly discussed.

Though some researchers use the term 'interference' to describe the response of an individual plant or plant species to its environment when this is modified by the presence of other individuals or species (Harper, 1961), the term 'competition' is preferred here. The words 'mixture' and 'mixed crop' are used interchangeably though some researchers prefer 'intercrop' and/or 'mixed crop' to describe specific crop mixtures.

\section{SOME MEASURES OF COMPETITION}

Two of the earliest attempts at measuring change in interacting populations over time were by Lotka (1925) and Volterra (1928) with application to animal ecology. The Lotka-Volterra differential equations expressed population changes over time in terms of the inhibitory effects of the competing populations and environmental limits. De Wit (1960) successfully applied these equations to interacting plant populations. He illustrated his analysis with experiments on an intercrop of barley and oats grown in a replacement series. In such series, 
mixtures range from one monoculture to the other in such a way that the sum $z_{1}+n z_{2}$ is always a constant, where $z_{1}$ and $z_{2}$ are the seed rates of the two species and $\mathrm{n}$ is a constant by which one species replaces the other in the series.

De Wit and van den Bergh (1965) characterized the performance of species in a replacement series by the relative yield total (RYT). The RYT is the sum of the relative yields of the species in the mixture. The relative yield is expressed as the ratio $r$ of the yield of a species in the mixture to its yield in monoculture. Then

$$
R Y T=r_{a}+r_{b}+\cdots+r_{n} .
$$

The value assumed by the RYT indicates whether the species are performing better in mixture than in monoculture, but only for that particular total density. Three situations can be distinguished:

$\mathrm{RYT}=1$. In this case, the species exclude each other. The yields of the two crops in a mixture can also be obtained by sowing part of the field with one crop and another part with the other. If it is observed in the range of seed densities normally grown, it represents the situation where there is no yield advantage in mixed cropping. Depending on the prices, it is economic to grow either one of the two species.

RYT $>1$. The two species are, at least, partly complementary in resource use. This can happen when their growth periods are only partly overlapping. The yields obtained in a mixture can only be achieved in monoculture by sowing a larger area partly with one crop and the remainder with the other. In these situations, there is a biological advantage in mixed cropping; whether it translates into economic advantage depends on prices.

$\mathrm{RYT}<1$. In such instances, allelopathic effects exist to the extent that one species 'poisons' the other. The yields obtained in a mixture can be achieved in monoculture by sowing a smaller area, partly with one crop and partly with the other. This kind of result has been observed when one species carries a virus that is transmitted to the other (de Wit, 1960).

Thus for replacement experiments, an RYT greater than 1 will always represent the case where there is some yield advantage in intercropping. The same cannot be inferred if the condition of fixed density is not met; density responses of the intercropped species are likely to be confounded with the effects of competition. Spitters (1980) discusses in some detail the fallacious conclusions that can be drawn from the RYT if the underlying conditions are not satisfied.

A popular alternative to the RYT, the land equivalent ratio (LER), was first conceptualized by Willey and Osiru (1972) as a basis for assessing yield advantage in situations where yield advantage in a mixture can occur without exceeding the yield of the higher yielding species. A yield advantage occurs if the mixture produces more yield from a given area of land than can be obtained by dividing that area of land into pure stands of the two species. The LER is defined as the relative land area under sole crops required to produce the yields achieved 
in intercropping (Willey, 1979a). Unlike the RYT it does not assume that total crop densities are constant.

The LER is widely used in assessing yield advantage from additive experiments where a fixed density of one species is grown with a variety of densities of the other. The LER is popular because it has no restrictive conditions for its use and puts different crops, irrespective of their level of yield, on a comparable basis.

\section{Limitations}

Some of the limitations with these measures of competition (or yield advantage) lie, not with the indices themselves, but with their application. Some researchers (Jolliffe et al., 1984; Connolly, 1986) observe that the conditions of a replacement experiment are so restrictive that no valid generalizations can be made. This is, however, true in general of mixed cropping experiments and not only of replacement experiments.

Replacement experiments repeated at a range of densities are said to be the only kind of design 'which comprehensively explores a range of proportions and densities of two competitors' (Silvertown, 1987), but since fixed density is a precondition for their use, they are not suitable for describing how the yield will behave in a mixture in which density is not held constant (Inouye and Schaffer, 1981). The RYT is thus not an appropriate measure of yield advantage for additive experiments.

Additive experiments (Harper, 1977; Silvertown, 1987) are currently in favour because they answer more directly agricultural questions about the extent to which the full yield of one crop is affected by another (Willey, 1979a; Spitters and van den Bergh, 1982). For example, additive designs are used quite extensively in crop/weed experiments because they mimic the real situation of a crop, planted at fixed density, but infested with weeds.

A major problem associated with the use of LERs in additive experiments is one of interpretation because the effects of total plant density and a high density of one crop on the other are compounded, that is, the proportional composition and the density of the mixture and their effects are completely confounded (Harper, 1977; Trenbath, 1976; Spitters, 1980). Trenbath (1976) underlines the importance of understanding how values of LER arise in formulating cropping recommendations. The danger of confounding beneficial interactions between components with a simple response to changed density can be overcome by using a range of densities so that it is possible to determine the optimal sole crop density for that site and season. However, most additive experiments are conducted with a single sole crop density, which is assumed to be optimum without further proof.

The crux of all LER calculations lies, then, in the choice of the standardizing sole crop yield. Although researchers, such as Willey and Osiru (1972) and Mead and Willey (1980), take care in pointing out what the standardizing sole crop yield should be, Francis (1989) points out that calculated and presented LERs ultimately depend on experimental objectives whose interpretation is at the discretion of the researcher. 


\section{Spitters' model on competition}

Spitters (1983) developed a method of estimating the degree of intra- and interspecific competition from the total biomass yield of species in a mixture. The model uses total biomass because its production is approximately linearly related to the particular resource that limits growth. The distribution of this resource is reflected in the biomass of each species.

Within a species, intra-specific competition expresses itself in the response of biomass to plant density. The hyperbola has been shown to describe this relationship (de Wit, 1960; Willey and Heath, 1969). The yield of species $j$ is given by:

$$
Y_{j}=\frac{B_{j} N_{j}}{B_{j} N_{j}+1} Q_{j}
$$

where $N_{j}$ (plants $\mathrm{m}^{-2}$ ) is the plant density of crop $j, Q_{j}\left(\mathrm{~g} \mathrm{~m}^{-2}\right)$ is the asymptotic yield at high density $\left(Y_{j}\right.$ will approach $Q_{j}$ at this density) and $B_{j}\left(m^{2}\right.$ plant $\left.{ }^{-1}\right)$ is the space occupied by a single plant when it stands far apart from others (and is hence free from competition); the yield of this single plant is given by $B_{j} Q_{j}$.

De Wit (1960) extended this equation to account for the effects of other species on the yield of a mixture. He also showed that the two equations can be expressed in terms of the same parameters $B_{1}$ and $B_{2}$, if the two species have similar growth curves and exclude each other in a replacement series at normal densities (RYT $=$ 1). The yield of species 1 and 2 in an intercrop is given by:

$$
\begin{aligned}
& Y_{1}=\frac{B_{1} N_{1}}{B_{1} N_{1}+B_{2} N_{2}+1} Q_{1} \\
& Y_{2}=\frac{B_{2} N_{2}}{B_{1} N_{1}+B_{2} N_{2}+1} Q_{2}
\end{aligned}
$$

One of the reasons some crop combinations give a yield advantage is because they are temporally complementary in resource capture (Willey, 1979a). In such cases, the species are only partly excluding each other (Hall, 1974). Spitters (1983) generalized de Wit's equations for such situations by introducing two new parameters into the equations:

$$
\begin{aligned}
& Y_{1}=\frac{B_{1} N_{1}}{1+B_{1} N_{1}+B_{1,2} N_{2}} Q_{1} \\
& Y_{2}=\frac{B_{2} N_{2}}{1+B_{2} N_{2}+B_{2,1} N_{1}} Q_{2}
\end{aligned}
$$

Unlike de Wit's equations, the above expressions are independent of each other in the parameters and allow for an estimation of competition effects in situations where the species in a mixture are complementary in resource use and the condition of fixed density is not met. From these equations it can now be inferred 
that one plant of species 1 has the same effect on the yield $Y_{1}$ as $B_{1,2} / B_{1}$ plants of species 2. Similarly, one plant of species 2 has the same effect on $Y_{2}$ as $B_{2,1} / B_{2}$ plants of species 1 .

However, there are some problems in estimating the parameters $B_{1}, B_{2}, B_{1,2}$ and $B_{2,1}$. Since these parameters can take values up to $\infty$, it is possible that the convergence criterion associated with the non-linear regression algorithm may not be met. Thus, even though the function is better visualized in de Wit's notation, Spitters' notation is used in this paper. Spitters expresses $Y_{1}$ and $Y_{2}$ as

$$
\begin{aligned}
& Y_{1}=\frac{N_{1}}{b_{1,0}+b_{1,1} N_{1}+b_{1,2} N_{2}} \\
& Y_{2}=\frac{N_{2}}{b_{2,0}+b_{2,1} N_{1}+b_{2,2} N_{2}}
\end{aligned}
$$

The parameters $b_{1,0}$ and $b_{2,0}$ (plants $g^{-1}$ ) are the reciprocal of the weights per plant of species 1 and 2 when they are free from competition. The parameters $b_{1,1}$ and $b_{2,2}$ are the reciprocals of the maximum biomass per unit area achieved at infinite density. It can be seen that Spitters' Equations $2 a$ and $2 b$ are the same as the generalized de Wit equations. The parameters $b_{1,0}, b_{1,1}$ and $b_{1,2}$ from Equation $2 \mathrm{a}$ are equal to $1 / \mathrm{B}_{1} \mathrm{Q}_{1}, 1 / \mathrm{Q}_{1}$ and $\mathrm{B}_{1,2} / \mathrm{B}_{1} \mathrm{Q}_{1}$.

Such simple mathematical expressions of complex biological processes necessarily introduce some compromise. Yields reach a maximum at finite rather than infinite densities, and at very low densities there is a linear relationship between plant density and yield rather than a hyperbolic one. However, the hyperbolic relationship has been shown by many researchers to be quite an acceptable description of the biological process of competition (Willey and Heath, 1969; de Wit, 1960).

\section{PRODUCTION POSSIBILITY FRONTIERS}

Economic analysis has not contributed much to the evaluation of productivity in intercropping, as evaluation in economic terms is considered inappropriate due to seasonal price fluctuations in inputs and lack of a cash economy in most areas where intercropping is practised (Beets, 1982, quoted in Ofori and Stern, 1987). The approach to assessing yield advantage developed in this section uses the concept of production possibility frontiers or curves from economics. This approach builds on the biological processes underlying intercropping and lends itself readily to economic interpretation.

A production function gives mathematical expression to the relationship between quantities of inputs employed and the output produced. This functional relationship is based on an examination of the many alternative ways in which inputs can be combined to produce any given output, and a selection of the most efficient ways of using inputs. The production frontier is thus the maximum 


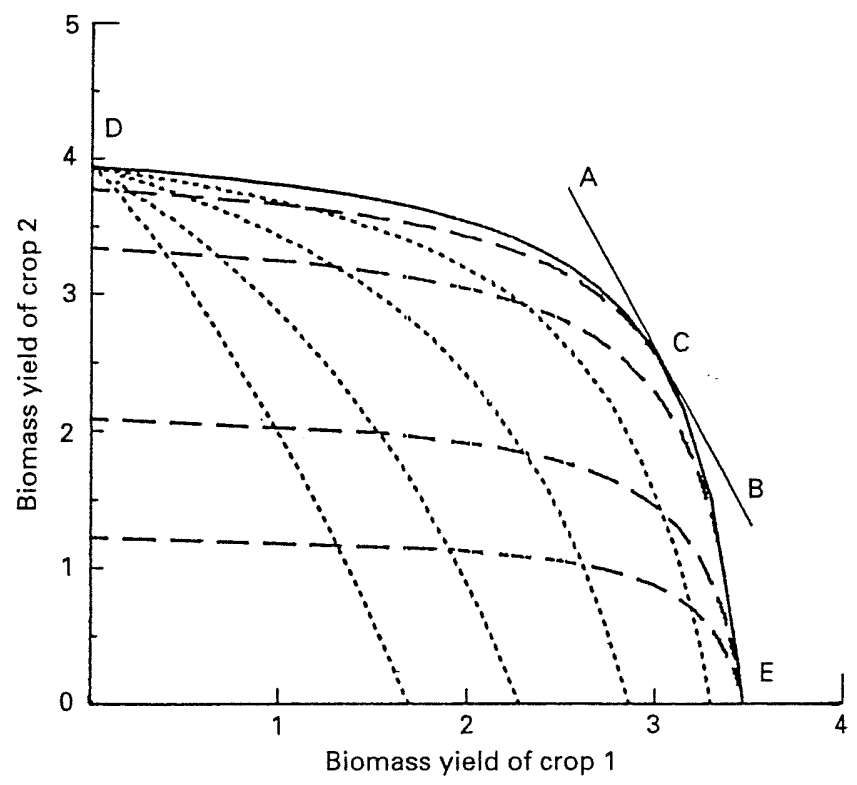

Fig. 1. The production frontier.

output obtainable from every possible input combination (Henderson and Quandt, 1971).

In a manner analogous to this argument, it is possible to summarize a relationship between two outputs, say yields from an intercrop. As discussed earlier in the paper, the yield of a mixture is dependent on the plant densities of the two crops. Assuming that resources have been used in the most efficient way, the production possibility frontier for the two yields gives the range of maximum yields that can be obtained after considering the yield from all possible plant density combinations. The frontier thus gives the best combination of plant densities. Every other combination is 'technically inefficient'.

A graphical derivation of a production possibility frontier ( $\mathrm{PPF}$ ) for an intercropping situation is shown in Fig. 1. The yields from crop 1 and crop 2 are plotted on the two axes. The dotted lines show combinations of yield for which the production process is not technically efficient. The curves radiating from the $y$-axis are obtained by keeping the density of crop 1 fixed at different levels, varying that of crop 2 and then calculating the corresponding yields using Spitters' equations. Similarly, the curves radiating upwards from the $\mathrm{x}$-axis are obtained by keeping the density of crop 2 fixed at different levels, varying that of crop 1 and calculating the corresponding yields. The envelope of all these curves is the production possibility frontier.

Knowledge of the PPF allows further economic analyses. The optimal point of production corresponds to the tangent of the price line (AB in Fig. 1) to the curve. A price line reflects a fixed value of production, that is, total value of the crops expressed as the sum of their constituent values. The line gives a locus of points of 
the same value of production for fixed prices and variable quantities of products. Hence, the value of production at $\mathrm{A}, \mathrm{C}$ and $\mathrm{B}$ are all the same.

Assuming input costs are constant, if the price of crop 1 increases, the price line will be steeper and the optimum point closer to $\mathrm{E}$, reflecting the need to produce more of crop 1 in order to maximize gross economic returns. Similarly, a price increase in crop 2 will result in a flatter curve and tip the economic balance towards crop 2.

The shape of the production possibility curve indicates the nature of the relationship between two crops. If the line is bowed outward from the origin, i.e. convex (as in Fig. 1), the two crops interact positively and are complementary; if bowed inward towards the origin, i.e. concave, the crops interact negatively and are allelopathic. A straight line indicates that the crops exclude each other and in a mixture their yield is no greater than if they had been planted as monocrops. The interpretation of the PPF is thus analogous to the LER or the RYT, except that the interpretation is not restricted to replacement series and not confounded by density effects.

Though similar to the LER or RYT, the PPF uses more information. Mathematically, global and local optima are accepted terms. The LER and RYT can be likened to local optima because they are restricted to some specific mixture combination from a limited range. The PPF makes it possible to examine the whole range of 'best' mixture combinations from some limited number of combinations. But the LER and RYT are more easily visualized because they are characterized by single numbers.

An index similar to the LER and RYT, but based on the PPF, has been suggested by Ranganathan et al. (1991). The yield advantage index (YAI) is the ratio of the area under the production possibility curve to the area under the triangle formed by the two axes and the line joining the sole crop yields on the axes. The line joining the sole crop yields is, in fact, the production possibility curve when the two crops in a mixture exclude each other. The YAI can take values between 0 and 2 . The maximum value illustrates the situation where the yields of the crops show no reduction when in a mixture. Since the YAI is based on the PPF, it provides more complete information than the LER or RYT.

\section{Estimation of the production possibility frontier}

The difficulty with estimating a frontier empirically from experimental data on yields, as in Ranganathan et al. (1991), is in ascertaining that the fitted curve actually corresponds with the production possibility frontier. Some points of the scatter, to which the curve is fitted, may be technically inefficient, while others must fall on the production frontier. A regression approach using least-squares is not at all appropriate for fitting a curve that corresponds to the frontier because of the possibility of inefficient points influencing its location.

It is desirable to derive a production possibility frontier from a priori knowledge of the processes that determine the outcome, in this case grain yields or biomass; to build, if possible, on the description of the biological processes underlying 
intercropping. An explanation of functional form restrictions, if any, should be possible in biological terms and justifiable on the basis of experimental evidence.

Information from Spitters' equations ( $2 \mathrm{a}$ and $2 \mathrm{~b}$ ) provide a strong base for the derivation of a production possibility frontier. As $\mathrm{N}_{1}$ and $\mathrm{N}_{2}$, plant densities of crops 1 and 2 in the intercrop, approach infinity, it follows that the yields of the two crops are given by:

$$
\begin{aligned}
& Y_{1}=\frac{1}{b_{1,1}+b_{1,2} \frac{N_{2}}{N_{1}}} \\
& Y_{2}=\frac{1}{b_{2,2}+b_{2,1} \frac{N_{1}}{N_{2}}}
\end{aligned}
$$

From Equations $3 \mathrm{a}$ and $3 \mathrm{~b}$ it follows that:

$$
\begin{aligned}
& \frac{N_{2}}{N_{1}}=\frac{1}{b_{1,2} Y_{1}}\left(1-b_{1,1} Y_{1}\right) \\
& \frac{N_{1}}{N_{2}}=\frac{1}{b_{2,1} Y_{2}}\left(1-b_{2,2} Y_{2}\right)
\end{aligned}
$$

By multiplying $4 \mathrm{a}$ and $4 \mathrm{~b}$, the following expression is obtained:

$$
\left(\frac{1}{b_{1,1} Y_{1}}-1\right)\left(\frac{1}{b_{2,2} Y_{2}}-1\right)=C
$$

where

$$
\mathrm{C}=\frac{\mathrm{b}_{1,2} \mathrm{~b}_{2,1}}{\mathrm{~b}_{1,1} \mathrm{~b}_{2,2}}
$$

Equation 5 defines a production possibility curve for outputs obtained by intercropping. It can be seen that $\mathrm{C}$ can take values between 0 and $\infty$. When $\mathrm{C}$ takes the value 1 , the function is a straight line; when $\mathrm{C}$ is greater than or less than 1 , the function is curved inwards or outwards, respectively. The function is flexible, requires few parameters to summarize the relationship between the two outputs and is easy to estimate by the use of non-linear regression.

The use of Equation 5, however, requires a word of caution. It is a mathematical expression of the interaction between plants in an intercrop and as such is valid only if certain mathematical conditions are satisfied. From the equation it is apparent that the parameters should be greater than zero. The expression no longer holds if any of the parameters, $b_{1,1}, b_{1,2}, b_{2,2}$ or $b_{2,1}$, approach zero. But this condition in no way devalues the usefulness of the method; if any of the parameters approach zero, it implies little or no interaction between the crops and the expression is no longer an accurate description of the situation. It is, of course, 
still possible to arrive at the production possibility frontier but only by drawing the envelopes as described in the previous section and as shown in Fig. 1.

Given that the parameters $b_{1,1}, b_{1,2} b_{2,2}$ and $b_{2,1}$ are greater than zero, the yield advantage index (YAI) is given by

$$
\mathrm{YAI}=\frac{\int_{0}^{1 / \mathrm{b}_{1,1}} \mathrm{Y}_{2} \mathrm{~d}\left(\mathrm{Y}_{1}\right)}{\frac{1}{2 \mathrm{~b}_{1,1} \mathrm{~b}_{2,2}}}
$$

where the numerator is the area under the frontier and the denominator, the area under the 'curve' formed when the crops exclude each other. On simplification, YAI can be expressed in terms of the parameters of Spitters' equations:

$$
\mathrm{YAI}=2\left[\frac{\mathrm{C} \ln (\mathrm{C})}{(\mathrm{C}-\mathrm{l})^{2}}-\frac{1}{\mathrm{C}-1}\right]
$$

where

$$
\mathrm{C}=\frac{\mathrm{b}_{1,2} \mathrm{~b}_{2,1}}{\mathrm{~b}_{1,1} \mathrm{~b}_{2,2}}
$$

YAI ranges between 0 and 2 depending on the values taken by $\mathrm{C}$. $\mathrm{C}$ can take values between 0 and $\infty$. Taking limits as $\mathrm{C}$ approaches 0 and $\infty$, we have

$$
\begin{aligned}
& \operatorname{Lim}_{C \rightarrow 0} \mathrm{YAI}=2 \\
& \operatorname{Lim}_{C \rightarrow 1} \mathrm{YAI}=1 \\
& \operatorname{Lim}_{C \rightarrow \infty} \mathrm{YAI}=0
\end{aligned}
$$

Thus, given that the hyperbolic function exists, the YAI is a sufficient statistic for the production possibility frontier.

From the production possibility curve, it is possible to calculate the ratio of seed densities to be sown in order to obtain the optimal yield combination at the prevailing prices. The point at which the price line is tangential to the PPF can be calculated by equating the first differential of the PPF to the slope of the price line. The slope is given by $-p_{1} / p_{2}$, where $p_{1}$ and $p_{2}$ are the existing prices of crops 1 and 2:

$$
-\frac{p_{1}}{p_{2}}=\frac{-b_{1,2} b_{2,1}}{\left[\left(b_{1,1} b_{2,2}-b_{1,2} b_{2,1}\right) Y_{1}-b_{2,2}\right]^{2}}
$$

Two solutions to $Y_{1}$ are obtained. The smaller of the two values is the optimal yield of crop 1. By substituting this value in Equation 4a, the ratio of seed densities of the species in the intercrop can be calculated. 
For crop combinations which result in yield advantage through mixed cropping, there is an economic advantage only when $-\mathrm{p}_{1} / \mathrm{p}_{2}$ is greater than the slope of the price line tangential to the PPF at $Y_{1}=0$ and smaller than the slope of the price line tangential to the PPF when $Y_{1}$ is maximum. These limits are expressed by:

$$
\left(-\frac{b_{1,2} b_{2,1}}{b_{2,2}^{2}},-\frac{b_{1,1}^{2}}{b_{1,2} b_{2,1}}\right)
$$

When this condition is not satisfied, it is more economic to plant one or the other crop in monoculture. The seed ratio will accordingly be very large or very small.

The method described here is applicable to situations where the value of the products is proportional to the total biomass alone and costs do not vary much for different plant densities as one moves along the frontier. Neither of the above conditions is excessively restrictive when one is interested in assessing biological productivity over a reasonable range of input use intensity.

\section{THE DATA SETS}

As examples of the use of the method, production possibility curves have been derived for experimental data from three intercropping trials. Along with the production frontier obtained from the function derived above, production possibility curves for plant densities ranging from technically inefficient to those that are efficient have been drawn. The examples demonstrate that the curve derived from Equation 5 corresponds to the frontier, and that the method is applicable to data from a wide range of situations.

\section{Data set 1}

The first set of data is from experiments conducted in Indonesia on maize (Zea mays L.) and groundnut (Arachis hypogaea L.) between 1978 and 1980 (van Hoof, 1987). The two crops have different growth durations; the time from sowing to maturity of the maize was 85 days and of the groundnut was 105 days. Replacement series were grown at different total densities in a randomized block design with four replicates. The recommended plant density for groundnut was 16 plants $\mathrm{m}^{-2}$ and for maize 8 plants $\mathrm{m}^{-2}$.

\section{Data set 2}

This data set is from de Wit's experiment of 1959 (de Wit, 1960) in the Netherlands with oats (Avena sativa var. Libertas) and barley (Hordeum vulgare var. Herta) and is used as an example of two species with similar growth curves crowding for the same space. The experiment was a replacement type repeated at a high density of 322 plants $\mathrm{m}^{-2}$ and at the recommended density of 32 plants $\mathrm{m}^{-2}$. Both trials were laid out as $5 \times 5$ lattices with two replicates. 
Data set 3

The third data set comes from an experiment conducted in 1979 at the ICRISAT Genter, Patancheru, India (ICRISAT, 1981b). The objective of the experiment was to determine the optimal total population of an intercrop of sorghum (Sorghum bicolor (L.) Moench) and pigeonpea (Cajanus cajan (L.) Millsp.). Pigeonpea populations with a $40 \%$ change $(2,2.8,4,5.6,7.8,10.9,15.3$ plants $\mathrm{m}^{-2}$ ) were systematically arranged at each of the four populations of sorghum $\left(4,11,18,32\right.$ plants $\left.\mathrm{m}^{-2}\right)$. Sole pigeonpea was planted at 4 plants $\mathrm{m}^{-2}$ and sole sorghum at each of the intercrop populations. The experiment was of the additive type and replicated four times.

\section{Discussion}

The parameters estimated from Spitters' equations show close correspondence with observed biomass (Table 1 and Fig. 2). The negative value of $b_{i, 0}$ for maize (Table 1) implies an increase in biomass per unit area for monocrop maize when the stand gets sparse. This is, of course, not possible. The negative value is caused by random errors arising from the fact that there are no yield observations at very wide spacings. The estimate here for $b_{i, 0}$ is not significantly different from 0 . In instances like this, it is best to use the value 0 for $b_{i, 0}$. The parameter $b_{i, 0}$ is the reciprocal of the weight of a plant when it stands far apart from other plants. From the observed yields in an experiment it is possible to calculate the highest yield per plant. The true value of $b_{i, 0}$ lies between 0 and the reciprocal of the highest observed yield per plant.

As the density of groundnut increased from 2.5 plants $\mathrm{m}^{-2}$ to 350 or more, the yield of sole groundnut increased till the increment was so small as to be

Table 1. Estimated parameters of the Spitters equations

\begin{tabular}{|c|c|c|c|c|}
\hline & $\begin{array}{c}b_{\mathrm{i}, 0} \\
\left.\text { (plants } 100 \mathrm{~g}^{-1}\right) \dagger\end{array}$ & $\begin{array}{c}b_{i, i} \\
\left(\mathrm{~m}^{2} 100 \mathrm{~g}^{-1}\right) \dagger\end{array}$ & $\begin{array}{c}b_{i, j} \\
\left(\mathrm{~m}^{2} 100 \mathrm{~g}^{-1}\right) \dagger\end{array}$ & Adj. $R^{2}$ \\
\hline \multicolumn{5}{|c|}{ Maize/groundnut (van Hoof, 1987) } \\
\hline Maize & $\begin{array}{l}0 \\
(0.065)\end{array}$ & $\begin{array}{c}0.193 \\
(0.004)\end{array}$ & $\begin{array}{c}0.027 \\
(0.007)\end{array}$ & 0.996 \\
\hline Groundnut & $\begin{array}{c}1.716 \\
(0.732)\end{array}$ & $\begin{array}{c}0.222 \\
(0.097)\end{array}$ & $\begin{array}{c}0.597 \\
(0.034)\end{array}$ & 0.983 \\
\hline \multicolumn{5}{|c|}{ Oats/barley (de Wit, 1960) } \\
\hline Oats & $\begin{array}{l}3.07 \\
(0.480)\end{array}$ & $\begin{array}{c}0.165 \\
(0.034)\end{array}$ & $\begin{array}{c}0.365 \\
(0.007)\end{array}$ & 0.993 \\
\hline Barley & $\begin{array}{c}3.695 \\
(0.379)\end{array}$ & $\begin{array}{c}0.180 \\
(0.010)\end{array}$ & $\begin{array}{c}0.071 \\
(0.006)\end{array}$ & 0.995 \\
\hline \multicolumn{5}{|c|}{ Sorghum/pigeonpea (ICRISAT, 1981b) } \\
\hline Sorghum & $\begin{array}{c}0.194 \\
(0.036)\end{array}$ & $\begin{array}{c}0.072 \\
(0.005)\end{array}$ & $\begin{array}{c}0.010 \\
(0.002)\end{array}$ & 0.990 \\
\hline Pigeonpea & $\begin{array}{c}0.018 \\
(0.045)\end{array}$ & $\begin{array}{c}0.215 \\
(0.003)\end{array}$ & $\begin{array}{c}0.021 \\
(0.009)\end{array}$ & 0.988 \\
\hline
\end{tabular}

†Standard errors are shown in parentheses. 

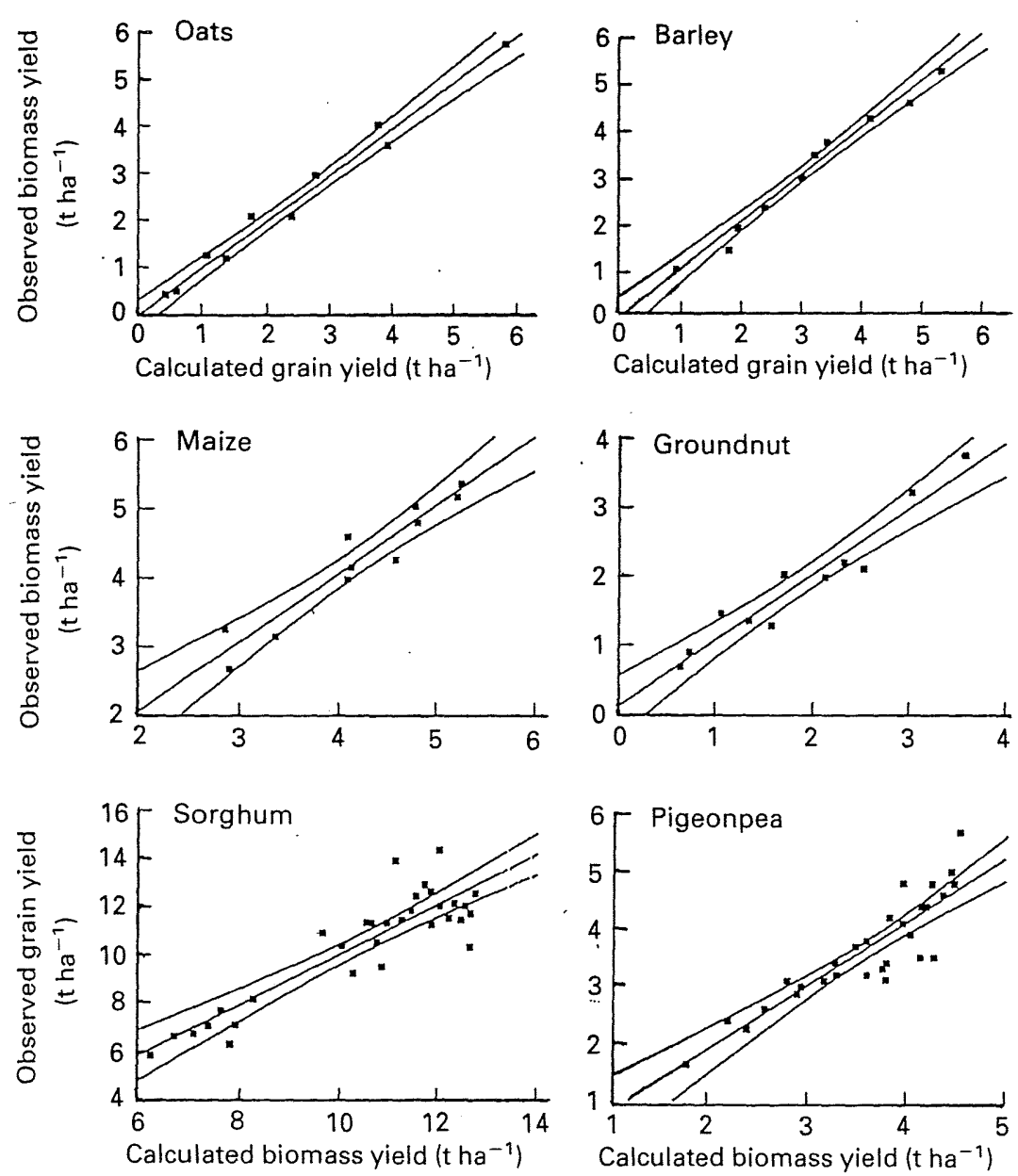

Fig. 2. Regression fit between observed and calculated yields at $90 \%$ confidence limits.

insignificant (Fig. 3a). Similar curves, but radiating upwards, were obtained by keeping the maize density constant at different levels and varying the groundnut density. The concentric nature of these inner curves is a reflection of the underlying asymptotic relationship between biomass and plant density. The solid line - the production frontier - gives the maximum yield that can be achieved.

The shape of the curve shows that there is a yield advantage in mixing maize with groundnut (YAI = 1.32): This result is consistent with prior agronomic knowledge about the relationship between the crops. In mixtures of grain crops, such as maize, with legumes a yield advantage..is generally the rule. In this experiment, the harvest index for both maize and groundnut is constant over the range of densities considered and the production frontier for grain can be calculated in the same way as the frontier for total biomass.

De Wit et al. (1979) found that for oats and barley, seed/straw ratios were hardly affected by density. The production frontier has thus been directly derived for 
seed yield (Fig. 3b). The shape of the curve shows that there is little yield advantage in mixed cropping ( $\mathrm{YAI}=0.7)$ and the largest yield, grain or cash, is obtained if the whole field is sown with either oats or barley, whichever yields more. However, de Wit also reported that farmers in the Netherlands planted oats and barley together because lodging in barley was found to be less when it was grown with a certain proportion of oats. In addition, although barley was preferred, farmers planted both on fields where the $\mathrm{pH}$ varied because on patches where the $\mathrm{pH}$ was low, oats yielded well and on patches where the $\mathrm{pH}$ was higher, barley grew well. In this way, farmers reduced their risks.

Sorghum/pigeonpea is an extremely common combination in many parts of India. Trials conducted at ICRISAT have shown that there are substantial yield advantages from this combination (Rao and Willey, 1983; Natarajan and Willey, $1980 \mathrm{a}, \mathrm{b})$. The strong positive interaction between a fast growing, early maturing
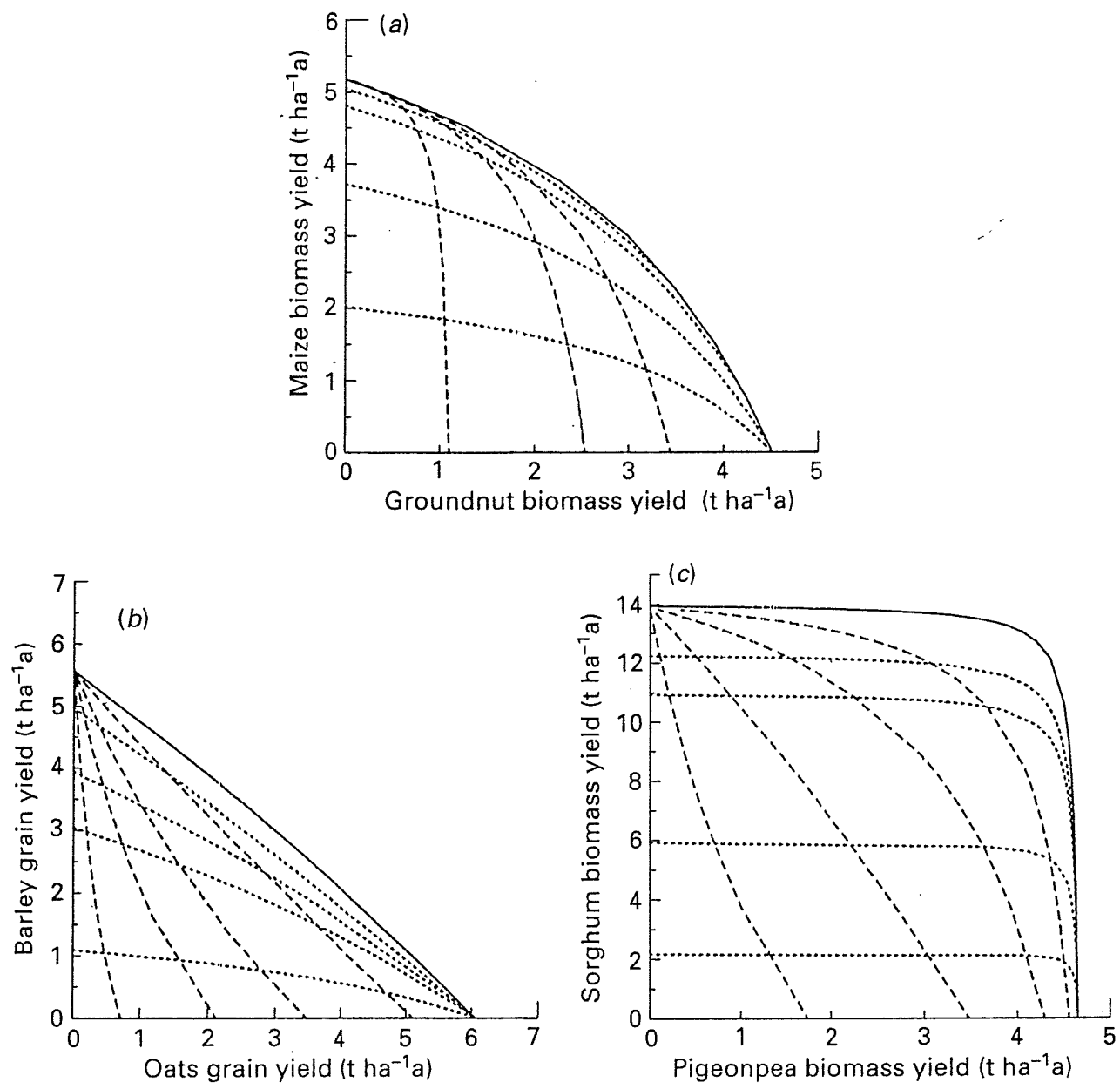

Fig. 3. Production possibility frontiers for (a) maize/groundnut, (b) oats/barley and (c) sorghum/ pigeonpea. 
crop and a slower growing one is quite obvious in the shape of the curve (YAI = 1.91) and is reflected in a large yield benefit (Fig. 3c). Pigeonpea yields are more or less constant for a very large range of sorghum densities. As in the other cases, the relationship between total dry matter and grain yield is characterized by a constant ratio. A frontier for grain can easily be derived using Equation 5.

In each of the examples of intercropping considered here, the grain/biomass relationship has been characterized by a constant ratio. This need not be the general case but in cases where this is not so, the production frontier cannot be calculated using Equation 5. The envelope as described in Fig. 1 must be drawn after calculating the grain yield as in the case of the seed/straw relationship for all points on the production frontier for biomass.

In many instances, input costs change as one moves along the frontier. Seed costs are particularly important and play a major role in a farmer's decision making process. For example, in mixed cropping with groundnut, farmers are restricted in the range of sowing densities available to them by the cost of groundnut seed. The cost per kilogram of seed for sowing is often four to five times the market price per kilogram of yield. There exists an optimum density beyond which the cost of seed required to achieve a certain level of yield exceeds the anticipated returns from the produce. Assuming all other input costs are constant, a production frontier where seed costs are taken into account can be numerically calculated as in Fig. 1 but Equation 5 cannot be used. Net yields can be calculated by the expression:

$$
Y_{i}=\frac{N_{i}}{b_{i, 0}+b_{i, i} N_{i}+b_{i, j} N_{j}}-f_{i} N_{i}
$$

where

$$
f_{i}=\frac{P_{s}}{P_{h}}(\text { seed weight })
$$

$P_{s}$ is the cost of the seed and $P_{h}$ is the market price for the harvested grain. By drawing the inner curves as in Fig. 1 and then the envelope, the 'profit frontier' is derived. The frontier for data from van Hoof's experiment (van Hoof, 1987) on the assumption that there is no cost associated with maize seed and the price of groundnut seed is five times the market price of the produce is shown in Fig. 4.

With fluctuations in prices, farmers should be and often are interested in changes in quantity of outputs produced as a response to changes in prices. This can be illustrated by a sensitivity analysis. Assuming that there is an existing market price for biomass and that input costs are constant along the frontier, changes in the relative production of one crop as a result of changes in price ratios are shown in Fig. 5. On the $\mathrm{x}$ axis is a range of ratios of the price of oats (or sorghum or maize) to that of barley (or pigeonpea or groundnut). The y axis gives the optimum yield of oats (or sorghum or maize) relative to the total optimum yield of the intercrop. 


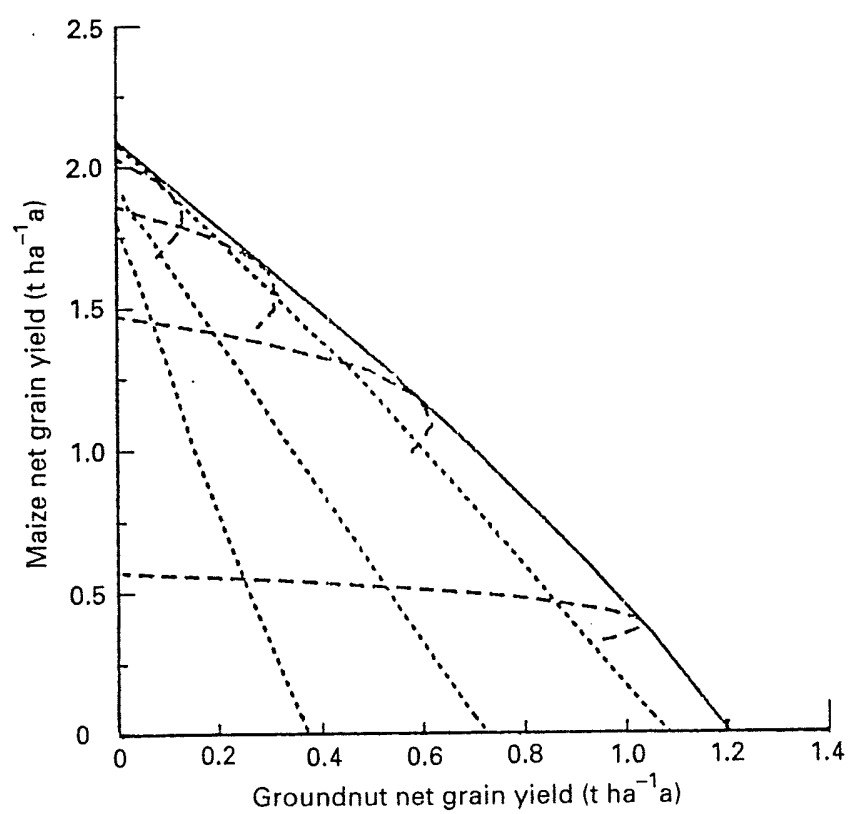

Fig. 4. 'Profit frontier' for maize/groundnut.

The response curve for oats and barley is akin to a step function. For a very small change in the price ratio of oats to barley ( 0.8 to 1 , the economic limits discussed in the previous section), oats, which constituted a very small fraction of the total yield, becomes the major component of the intercrop. When the price

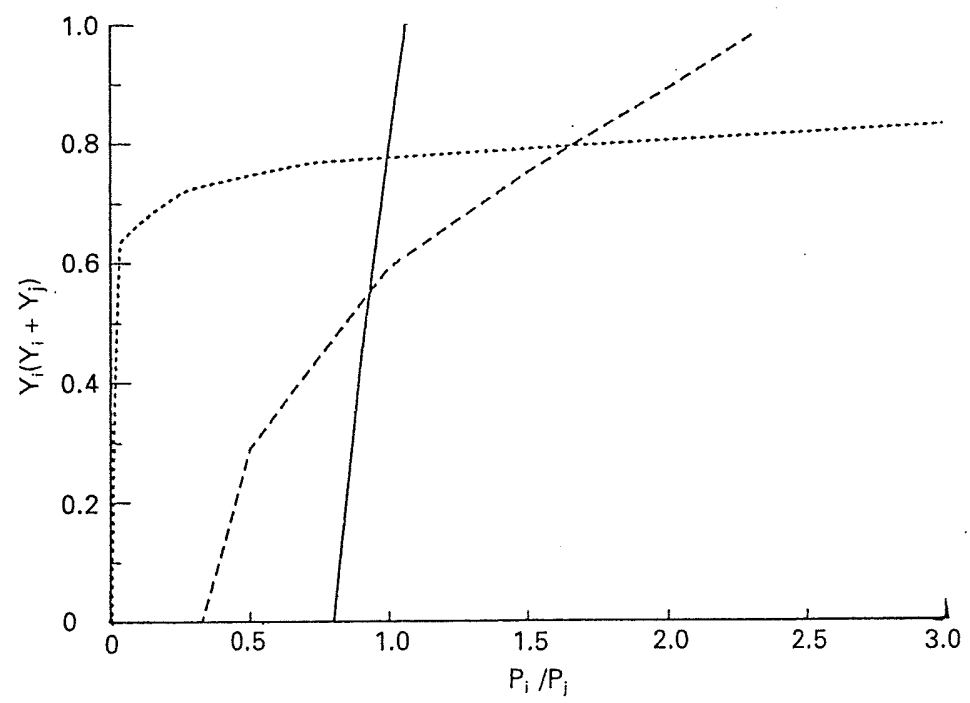

Fig. 5. Change in output $\left(Y_{i} /\left(Y_{i}+Y_{j}\right)\right.$ as a response to change in prices $\left(P_{i} / P_{j}\right)$ for two intercropped species, $i$ and $j($ oats and barley; respectively). 
ratio of oats to barley is slightly greater than the ratio where the 'step' in Fig. 5 occurs, it makes economic sense to grow only oats. The intercrop of sorghum and pigeonpea is a contrasting case. Only at very, very low prices of sorghum relative to pigeonpea will farmers plant sole pigeonpea. But as the price ratio increases from close to 0 to 0.5 , the proportion of sorghum in the intercrop increases from a very small quantity to $76 \%$. That this proportion stays more or less the same for large values on the $\mathrm{x}$ axis is indicative of the fact that intercropped sorghum and pigeonpea show huge yield advantages.

The third intercrop combination of maize and groundnut shows greater sensitivity to changes in prices. The proportion of maize in the intercrop shows a gradual change with an increase in its price relative to that of groundnut. In order to maximize profits, farmers would need to respond even to slight changes in prices by altering the proportion of the crops in the intercrop.

\section{CONCLUSIONS}

Production possibility frontiers have long been used as a theoretical device to express the relationship between two outputs. The frontier itself, however, has not always been easy to estimate. The method suggested here to derive a production frontier is built on strong a priori knowledge of the underlying biological processés in intercropping. It is flexible, easily adjusted for economic factors affecting production, and imposes few restrictions on the parameters. Several of the problems of estimation normally encountered with empirical models are overcome.

Furthermore, it has several advantages over the existing methods of analysing data from intercropping trials. It is applicable to the results from different kinds of trials, is a global measure of biological productivity and provides more information than existing methods.

Acknowledgements. The author would like to thank Professor G. T. de Wit and Drs T. S. Walker and C. K. Ong for their guidance. Approved as ICRISAT Journal Article No. 1257.

\section{REFERENCES}

Beets, W. C. (1982). Multiple Cropping and Tropical Farming Systems. Boulder, Colorado: Westview Press. Connolly, J. (1986). On difficulties with replacement series methodology in mixture experiments. Journal of Applied Ecology, 23:125-37.

de Wit, C. T. (1960). On competition. Verslag Landbouwkundig Onderzoek 66.8.

de Wit, C. T. \& van den Bergh, J. P. (1965) Competition between herbage plants. Netherlands Journal of Agricultural Sciences 13:212-21.

de Wit, C. T., van Laar, H. H. \& van Keulen, H. (1979). Physiological potential of crop production. In Plant Breeding Perspectives, 47-82 (Eds J. Sneep and A. J. T. Hendriksen). Wageningen: Pudoc.

Francis, C. A. (1989). Biological efficiencies in multiple-cropping systems. Advances in Agronomy 42:1-36. 